Electronic Supplementary Information (ESI)

\title{
Dissociative Oxygen Reduction Reaction Mechanism on the Neighboring Active Sites of Boron-Doped Pyrolyzed Fe-N-C Catalyst
}

Adhitya Gandaryus Saputro, ${ }^{\star},+, \S$ Apresio Kefin Fajrial, ${ }^{\ddagger}$ Arifin Luthfi Maulana, ${ }^{\dagger}$ Fadjar

Fathurrahman, ${ }^{\dagger, \S}$ Mohammad Kemal Agusta, ${ }^{\dagger, \S}$ Fiki Taufik Akbar, ${ }^{\boldsymbol{T}}$ and Hermawan Kresno Dipojono ${ }^{* *}, \uparrow, \S$

† Advanced Functional Materials Research Group, Institut Teknologi Bandung, Jl.Ganesha 10, Bandung 40132, Indonesia.

‡ Department of Mechanical Engineering, University of Colorado, Boulder, CO 80309, USA.

I Theoretical High Energy Physics Research Group, Institut Teknologi Bandung, J.Ganesha 10, Bandung 40132, Indonesia.

$\S$ Research Center for Nanoscience and Nanotechnology, Institut Teknologi Bandung, Jalan Ganesha no. 10, Bandung, Indonesia.

E-mail: *ganda@tf.itb.ac.id ; ** dipojono@tf.itb.ac.id 


\section{Microkinetic simulations}

\section{A. Rate Constant Calculation}

In calculating the rate constants, transition state theory model is assumed. We differentiate the calculation for non-electrochemical steps from electrochemical one. For non-electrochemical reaction of step- $i$,

$$
k_{i}=\frac{k_{\mathrm{B}} T}{h} \exp \left(-\frac{G_{a, i}}{k_{\mathrm{B}} T}\right)
$$

where $G_{a, i}$ is the activation free energy of step-i. For electrochemical reaction of step-i,

$$
k_{i}=A_{i} \exp \left(-\frac{G_{a, i}^{\circ}}{k_{\mathrm{B}} T}\right) \exp \left(-\frac{e \beta\left(U-U^{\circ}{ }_{i}\right)}{k_{\mathrm{B}} T}\right)
$$

where $G_{a, i}^{\circ}$ is the activation free energy of step- $i$ at the reversible potential of step- $i\left(U^{\circ}{ }_{i}\right)$ and $\beta$ is the symmetry factor. We set $\beta=0.5$ equally to all observed electrochemical steps. We use $A_{i}=1 \times 10^{9} \mathrm{~s}^{-1}$ for all protonation reactions [1]. For both non-electrochemical and electrochemical steps, the rate constant is evaluated at $T=298 \mathrm{~K}$. For the reverse steps,

$$
k_{-i}=\frac{k_{i}}{K_{i}}
$$

where $K_{i}$ is the equilibrium constant of step-i which takes the form below.

$$
K_{i}=\exp \left(-\frac{\Delta G_{i}}{k_{\mathrm{B}} T}\right)
$$

The reaction free energy, $\Delta G_{i}$, for electrochemical steps depends on the applied potential, $U$. The relationship can be written as

$$
\Delta G_{i}=\Delta G^{\circ}{ }_{i}+e U
$$

while $\Delta G_{i}$ for non-electrochemical steps is potential independent.

[1] Hansen, H. A., Viswanathan, V., Nørskov, J. K. Unifying Kinetic and Thermodynamic Analysis of $2 \mathrm{e}^{-}$and $4 \mathrm{e}^{-}$Reduction of Oxygen on Metal Surfaces. J. Phys. Chem. C 2014, 118, 6706-6718.

\section{B. Microkinetic Model Derivation}

In this section, we develop a thorough process of deriving microkinetic model adopted in this work. As an example, we use the reaction network taking place in $\mathrm{FeN}_{4} \mathrm{GBN}$ of path $\mathrm{B}$. For other paths, the derivations steps are similar. The elementary reactions and its numbering are

R1:

$$
\mathrm{O}_{2}(\mathrm{~g})+{ }^{*} \rightleftharpoons{ }^{*} \mathrm{O}_{2}
$$

R2:

$$
{ }^{*} \mathrm{O}_{2}+{ }^{*} \rightleftharpoons{ }^{*} \mathrm{O}[\mathrm{B}]+{ }^{*} \mathrm{O}[\mathrm{Fe}]
$$

R3:

$$
{ }^{*} \mathrm{O}[\mathrm{B}]+{ }^{*} \mathrm{O}[\mathrm{Fe}]+\mathrm{H}^{+}+\mathrm{e}^{-} \rightleftharpoons{ }^{*} \mathrm{OH}[\mathrm{B}]+{ }^{*} \mathrm{O}[\mathrm{Fe}]
$$

R4:

$$
{ }^{*} \mathrm{OH}^{[\mathrm{B}]}+{ }^{*} \mathrm{O}[\mathrm{Fe}]+\mathrm{H}^{+}+\mathrm{e}^{-} \rightleftharpoons{ }^{*} \mathrm{O}[\mathrm{Fe}]+{ }^{*}+\mathrm{H}_{2} \mathrm{O}
$$




$$
\begin{aligned}
& \text { R5: }{ }^{*} \mathrm{O}[\mathrm{Fe}]+{ }^{*}+\mathrm{H}_{2} \mathrm{O}+\mathrm{H}^{+}+\mathrm{e}^{-} \rightleftharpoons{ }^{*} \mathrm{OH}[\mathrm{Fe}]+{ }^{*}+\mathrm{H}_{2} \mathrm{O} \\
& \text { R6: }{ }^{*} \mathrm{OH}^{[\mathrm{Fe}]}+{ }^{*}+\mathrm{H}_{2} \mathrm{O}+\mathrm{H}^{+}+\mathrm{e}^{-} \rightleftharpoons 2^{*}+2 \mathrm{H}_{2} \mathrm{O}
\end{aligned}
$$

$\mathrm{R} 1$ and $\mathrm{R} 2$ are non-electrochemical reactions; therefore equation (1) is used to calculate its rate constant. The rest steps use equation (2).

The rate of change of all coverages is expressed as

$$
\frac{d \theta_{j}}{d t}=\sum_{k} n_{k} r_{k}
$$

where $\theta_{j}$ is the fractional coverage of species $j, n_{k}$ is the number of adsorbate $j$ (its stoichiometric coefficient) being consumed (produced) in step $k$ with its associated mathematical sign $-(+)$, and $r_{k}$ is the step $k$ where species $j$ is involved. Herein, the rate law of each elementary step can be written as

$$
\begin{aligned}
& r_{1}=k_{1} x_{\mathrm{O}_{2}} \theta_{*}-k_{-1} \theta_{\mathrm{O}_{2}} \\
& r_{2}=k_{2} \theta_{\mathrm{O}_{2}} \theta_{*}-k_{-2} \theta_{\mathrm{O}[\mathrm{B}]} \theta_{\mathrm{O}[\mathrm{Fe}]} \\
& r_{3}=k_{3} \theta_{\mathrm{O}[\mathrm{B}]}-k_{-3} \theta_{\mathrm{OH}[\mathrm{B}]} \\
& r_{4}=k_{4} \theta_{\mathrm{OH}[\mathrm{B}]}-k_{-4} \theta_{*} x_{\mathrm{H}_{2} \mathrm{O}} \\
& r_{5}=k_{5} \theta_{\mathrm{O}[\mathrm{Fe}]}-k_{-5} \theta_{\mathrm{OH}[\mathrm{Fe}]} \\
& r_{6}=k_{6} \theta_{\mathrm{OH}[\mathrm{Fe}]}-k_{-6} \theta_{*} x_{\mathrm{H}_{2} \mathrm{O}}
\end{aligned}
$$

$x_{\mathrm{O}_{2}}$ and $x_{\mathrm{H}_{2} \mathrm{O}}$ are the mole fraction of $\mathrm{O}_{2}$ and $\mathrm{H}_{2} \mathrm{O}$, respectively. We use the same procedure in reference [1] to calculate the mole fraction by using Henry's law. We set $x_{\mathrm{O}_{2}}=2.34 \times 10^{-5}$ corresponding to partial pressure $\mathrm{O}_{2}$ of $1 \mathrm{~atm}$ and $x_{\mathrm{H}_{2} \mathrm{O}}=1$. Both values are set to be constant. The differential equations then can be written as

$$
\begin{aligned}
& \frac{d \theta_{\mathrm{O}_{2}}}{d t}=r_{1}-r_{2} \\
& \frac{d \theta_{\mathrm{O}[\mathrm{B}]}}{d t}=r_{2}-r_{3} \\
& \frac{d \theta_{\mathrm{OH}[\mathrm{B}]}}{d t}=r_{3}-r_{4} \\
& \frac{d \theta_{\mathrm{O}[\mathrm{Fe}]}}{d t}=r_{2}-r_{5} \\
& \frac{d \theta_{\mathrm{OH}[\mathrm{Fe}]}}{d t}=r_{5}-r_{6} \\
& \frac{d \theta_{*}}{d t}=r_{6}-r_{1}
\end{aligned}
$$

By these equations, the coverage conservation is guaranteed. The differential equations set are solved numerically. The TOF is defined as the lowest $r_{i}$

$$
\mathrm{TOF}=\min \left\{r_{i}\right\} \text { where } i=1, \ldots, 6
$$




\section{ADDITIONAL FIGURES}

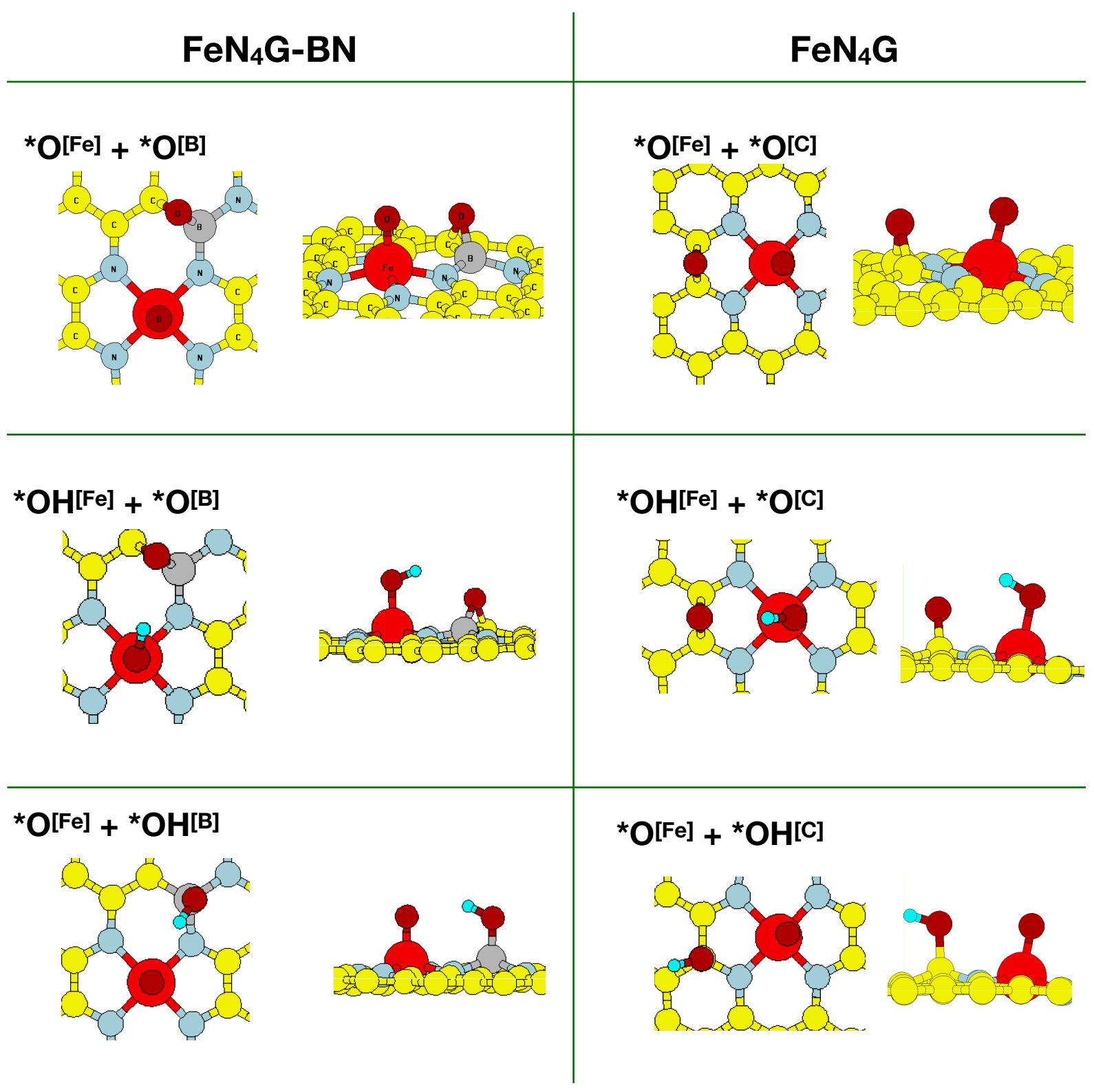

Figure S1. The geometries of ORR-related molecules adsorption on FeN 4 G-BN and undoped $\mathrm{FeN}_{4} \mathrm{G}$ systems. Reaction 4-6b. 


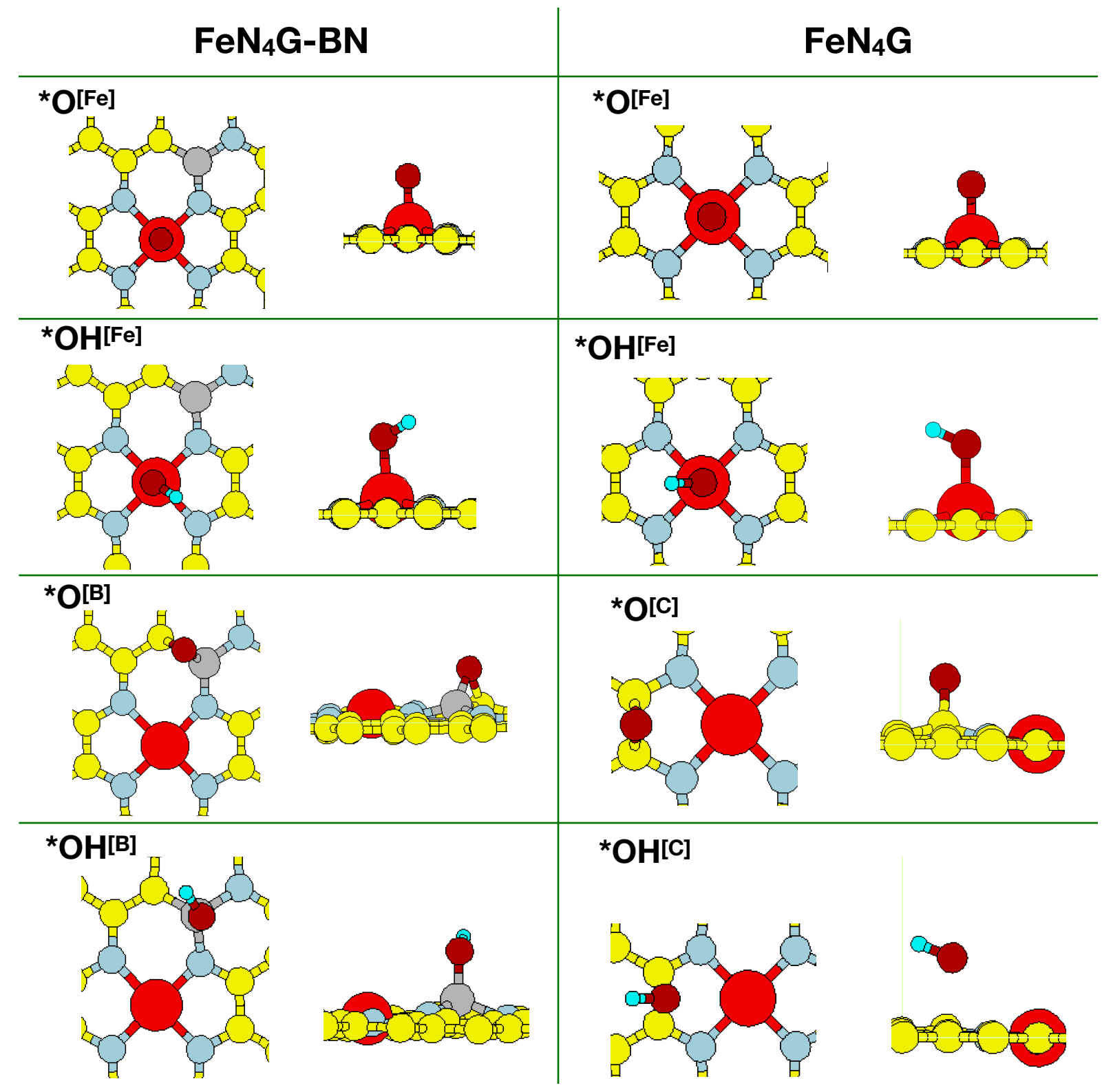

Figure S2. The geometries of ORR-related molecules adsorption on $\mathrm{FeN}_{4} \mathrm{G}-\mathrm{BN}$ and undoped $\mathrm{FeN}_{4} \mathrm{G}$ systems. Reaction 7a-8b. 


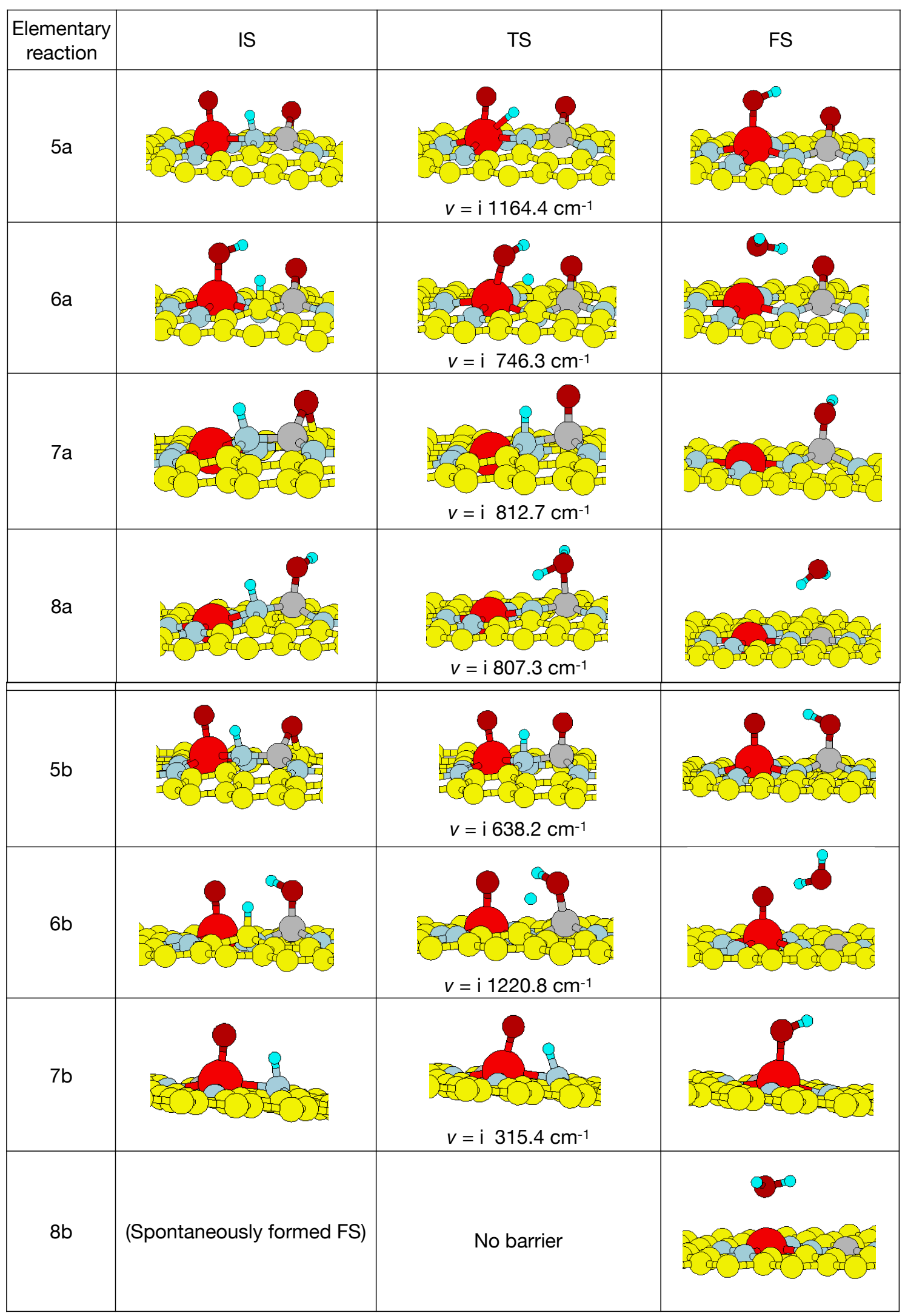

Figure S3. Structures of initial state (IS), transition state (TS) and final state (FS) of oxygen reduction elementary reactions through the dissociation pathway on $\mathrm{FeN}_{4} \mathrm{G}$ $\mathrm{BN}$ system using water solvated model. 


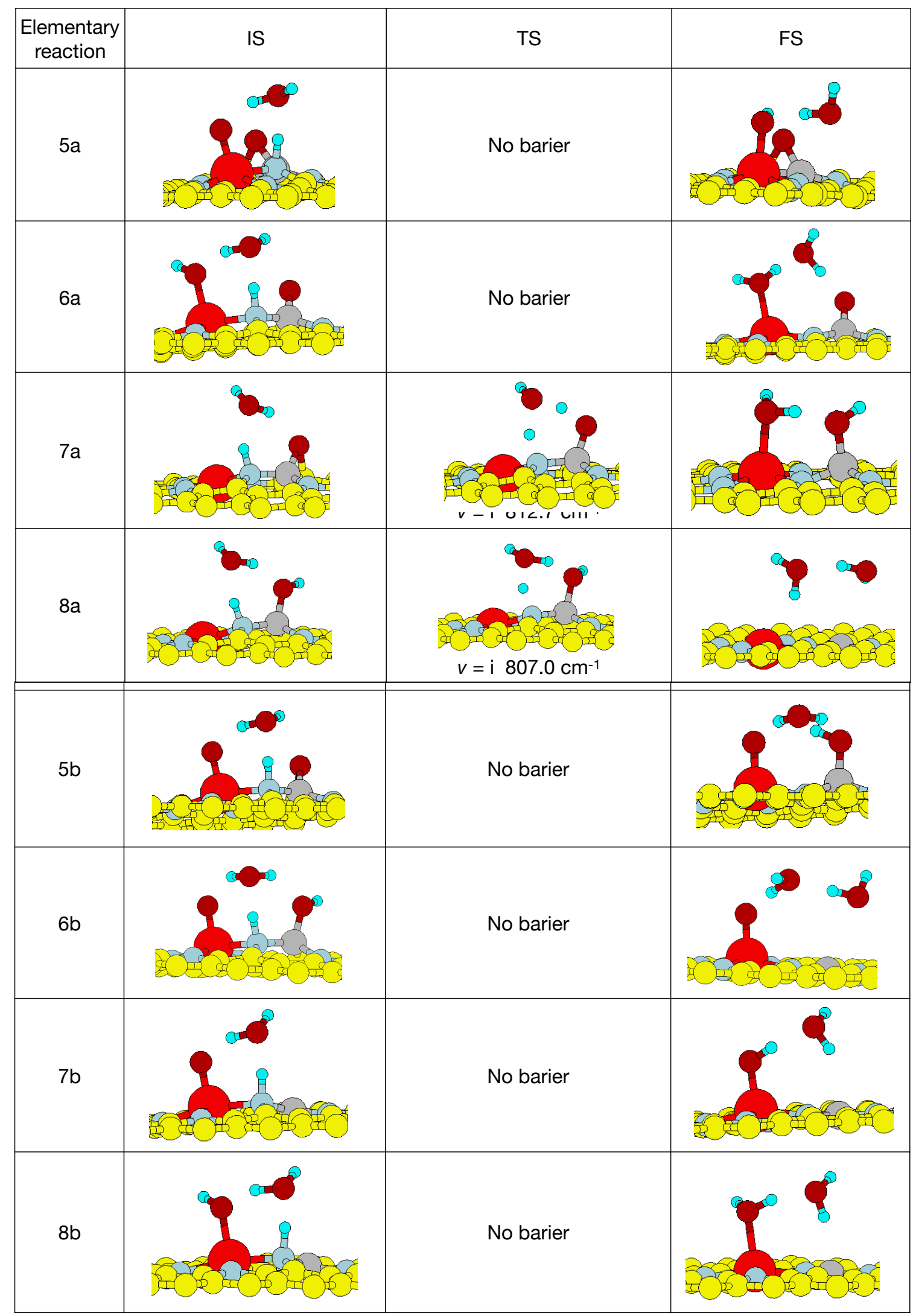

Figure S4. Structures of initial state (IS), transition state (TS) and final state (FS) of oxygen reduction elementary reactions through the dissociation pathway on $\mathrm{FeN}_{4} \mathrm{G}$ BN system using $\mathrm{H}$-shuttling model. 


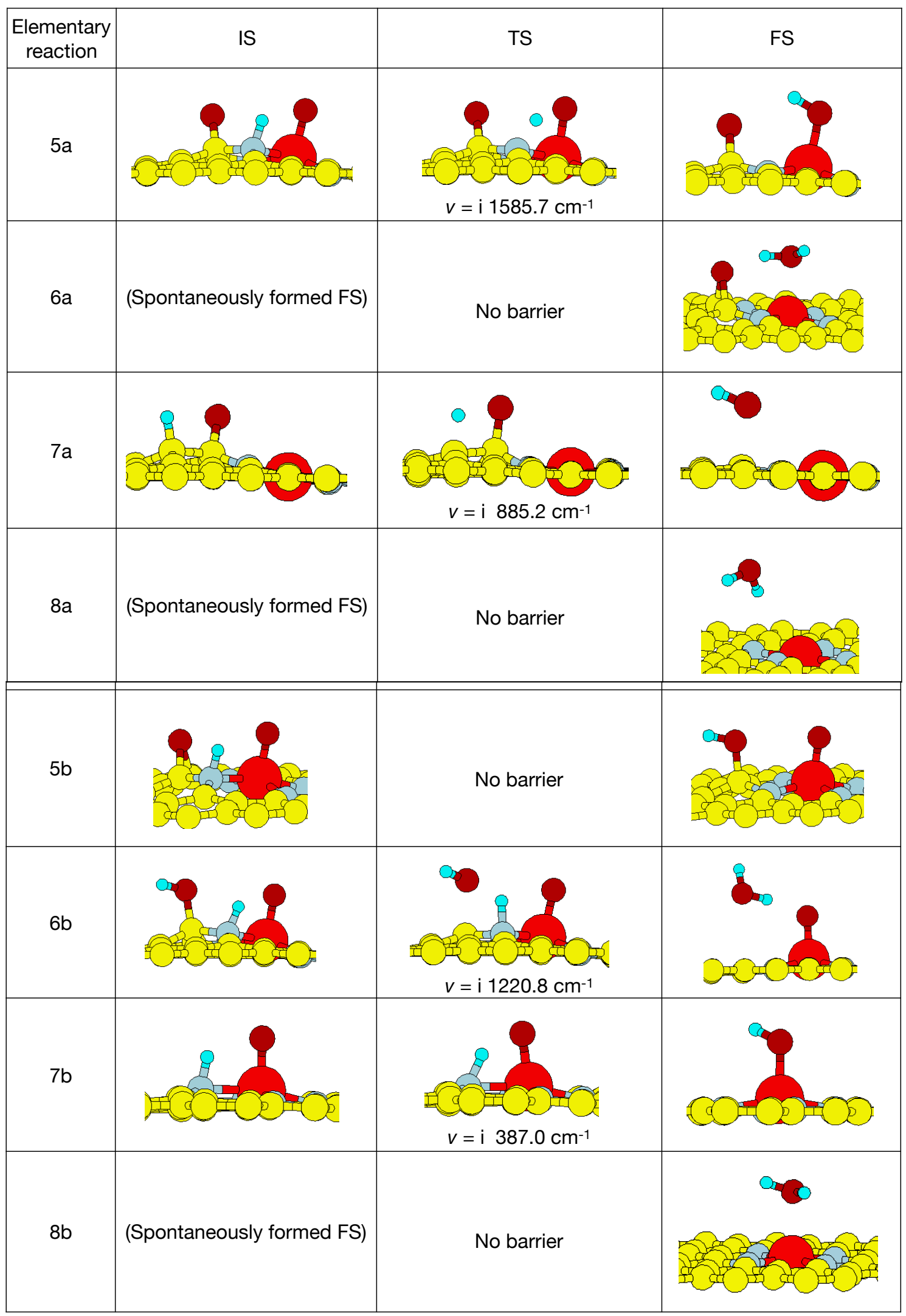

Figure S5. Structures of initial state (IS), transition state (TS) and final state (FS) of oxygen reduction elementary reactions through the dissociation pathway on $\mathrm{FeN}_{4} \mathrm{G}$ system using water solvated model. 


\begin{tabular}{|c|c|c|c|}
\hline $\begin{array}{l}\text { Elementary } \\
\text { reaction }\end{array}$ & IS & TS & FS \\
\hline $5 a$ & & & \\
\hline $6 a$ & (Spontaneously formed FS) & No barrier & \\
\hline $7 a$ & & No barrier & \\
\hline $8 a$ & & No barrier & \\
\hline $5 b$ & & No barrier & \\
\hline $6 b$ & (Spontaneously formed FS) & No barrier & \\
\hline $7 b$ & & No barrier & \\
\hline $8 b$ & (Spontaneously formed FS) & No barrier & \\
\hline
\end{tabular}

Figure S6. Structures of initial state (IS), transition state (TS) and final state (FS) of oxygen reduction elementary reactions through the dissociation pathway on $\mathrm{FeN}_{4} \mathrm{G}$ system using $\mathrm{H}$-shuttling model. 


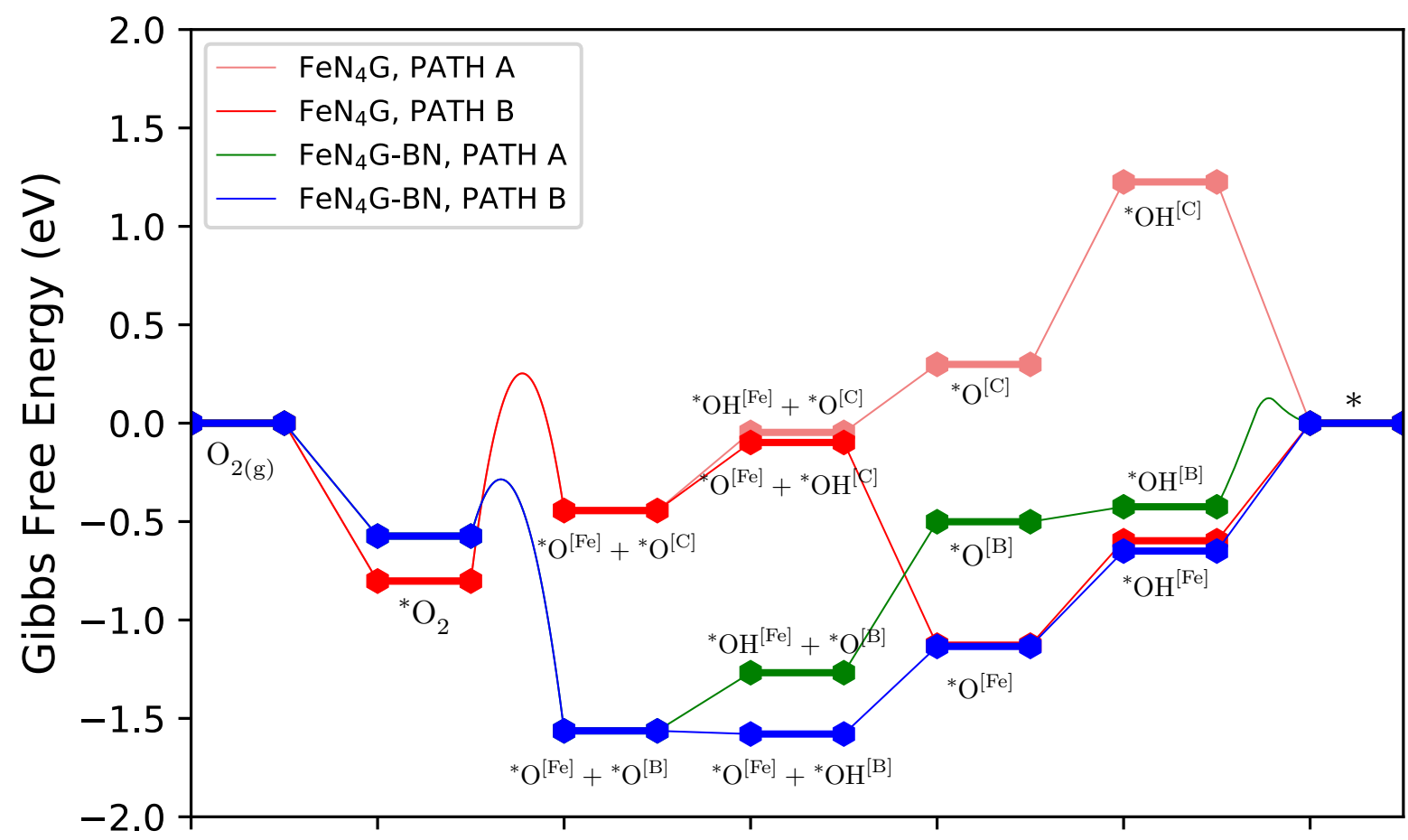

Figure S7. ORR free energy profiles for dissociative mechanism on the neighboring $\mathrm{FeN}_{4}$ and $\mathrm{B}_{\text {subs }}$ sites of $\mathrm{FeN}_{4} \mathrm{G}-\mathrm{BN}$ system compared to that of the undoped $\mathrm{FeN}_{4} \mathrm{G}$ system at $U=1.23 V_{S H E}\left(U=0.4 V_{R H E} ; H=14\right)$.

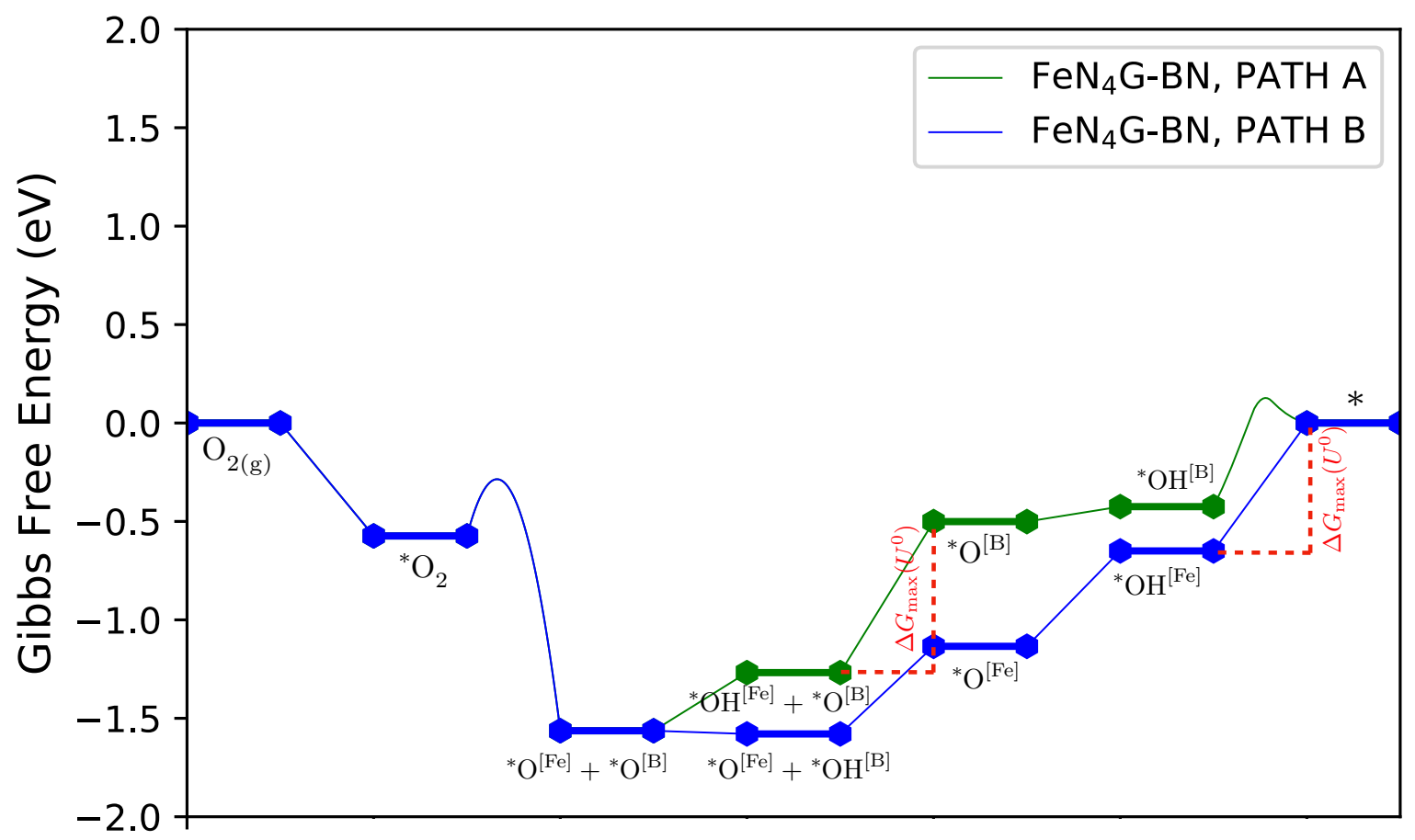

Figure S8. ORR free energy profiles for dissociative mechanism on the neighboring $\mathrm{FeN}_{4}$ and $B_{\text {subs }}$ sites of $\mathrm{FeN} \mathrm{N}_{4} \mathrm{G}-\mathrm{BN}$ system at $\mathrm{U}=1.23 \mathrm{~V}_{\mathrm{SHE}}\left(\mathrm{U}=0.4 \mathrm{~V}_{\mathrm{RHE}} ; \mathrm{pH}=14\right)$. The elementary steps that give the overpotentials $\left[e \eta=\Delta G_{\max }\left(U^{0}\right)\right]$ on each reaction pathways are indicated in the figure. 


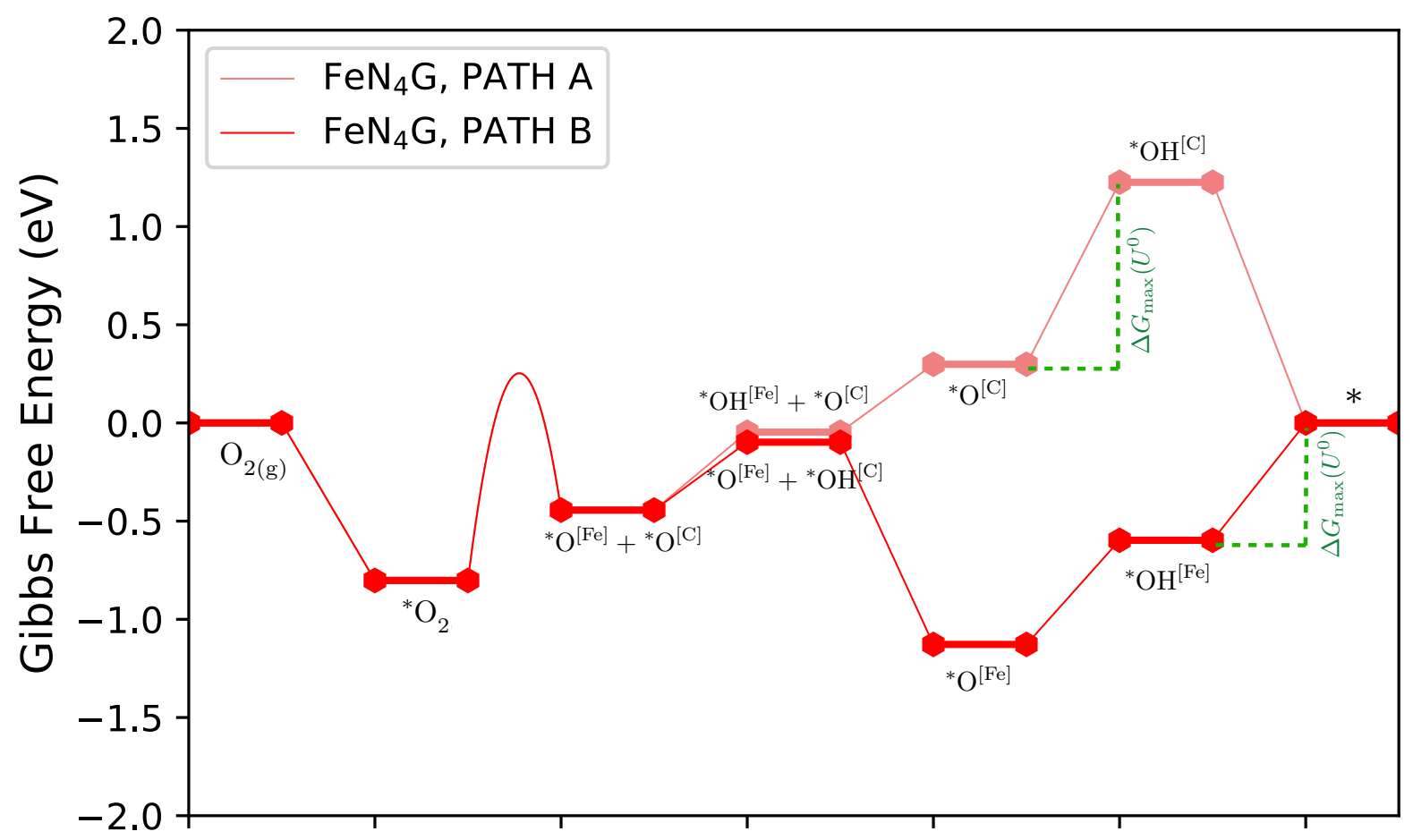

Figure S9. ORR free energy profiles for dissociative mechanism on the undoped $\mathrm{FeN}_{4} \mathrm{G}$ system at $\mathrm{U}=1.23 \mathrm{~V}_{\mathrm{SHE}}\left(\mathrm{U}=0.4 \mathrm{~V}_{\mathrm{RHE}} ; \mathrm{pH}=14\right)$. The elementary steps that give the overpotentials $\left[e \eta=\Delta G_{\max }\left(U^{0}\right)\right.$ ] on each reaction pathways are indicated in the figure.

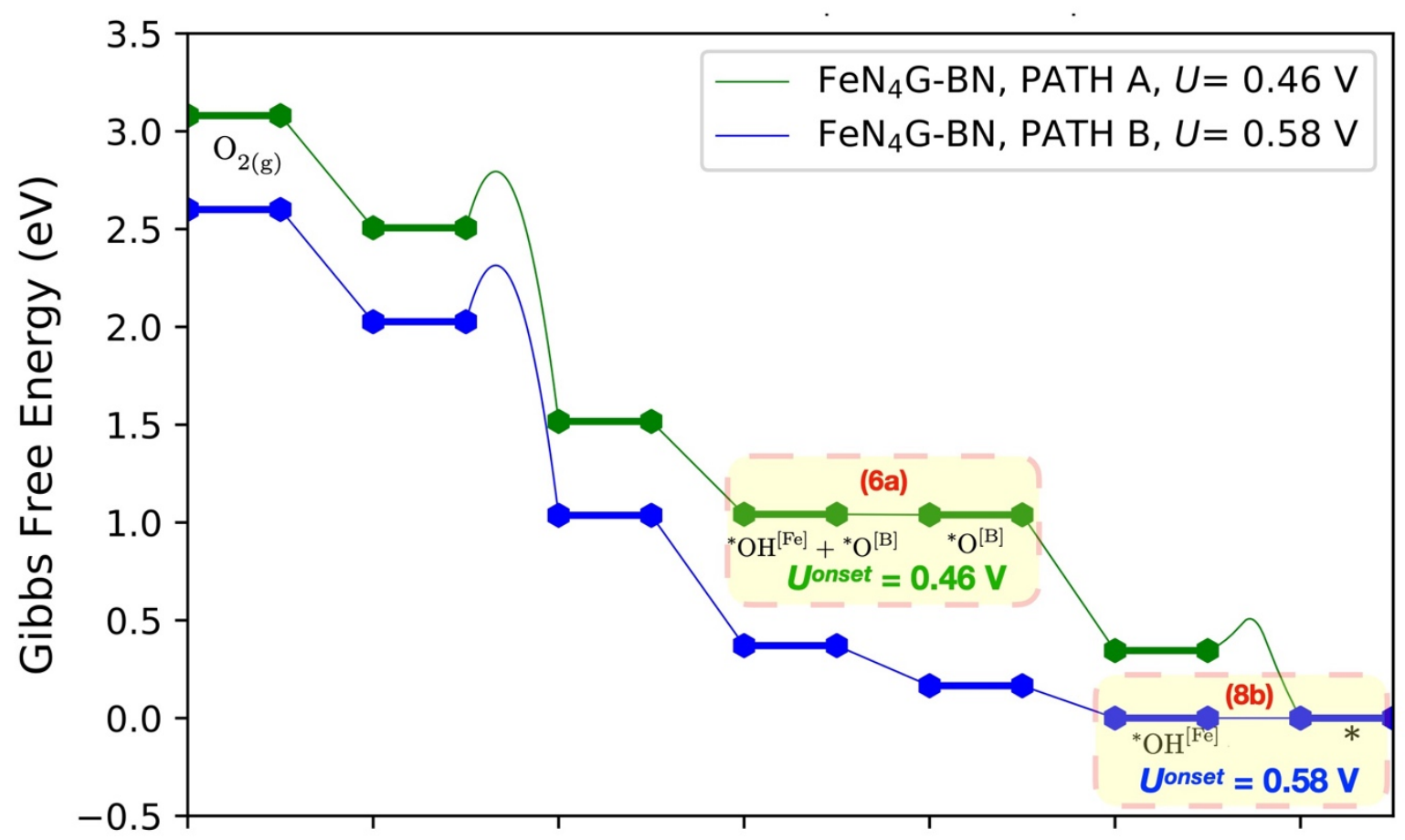

Figure S10. ORR free energy profiles for dissociative mechanism on the neighboring $\mathrm{FeN}_{4}$ and $\mathrm{B}_{\text {subs }}$ sites of $\mathrm{FeN} \mathrm{N}_{4} \mathrm{G}-\mathrm{BN}$ system at $U=0.46 \mathrm{~V}$ for pathway $\mathrm{A}$ and $U=0.58 \mathrm{~V}$ for pathway B. At these potentials, $\Delta G(U)$ of reaction (6a) and (8b) are equal to zero. The free energy profiles for these reaction pathways start to have uphill profiles at potential higher than these values. 


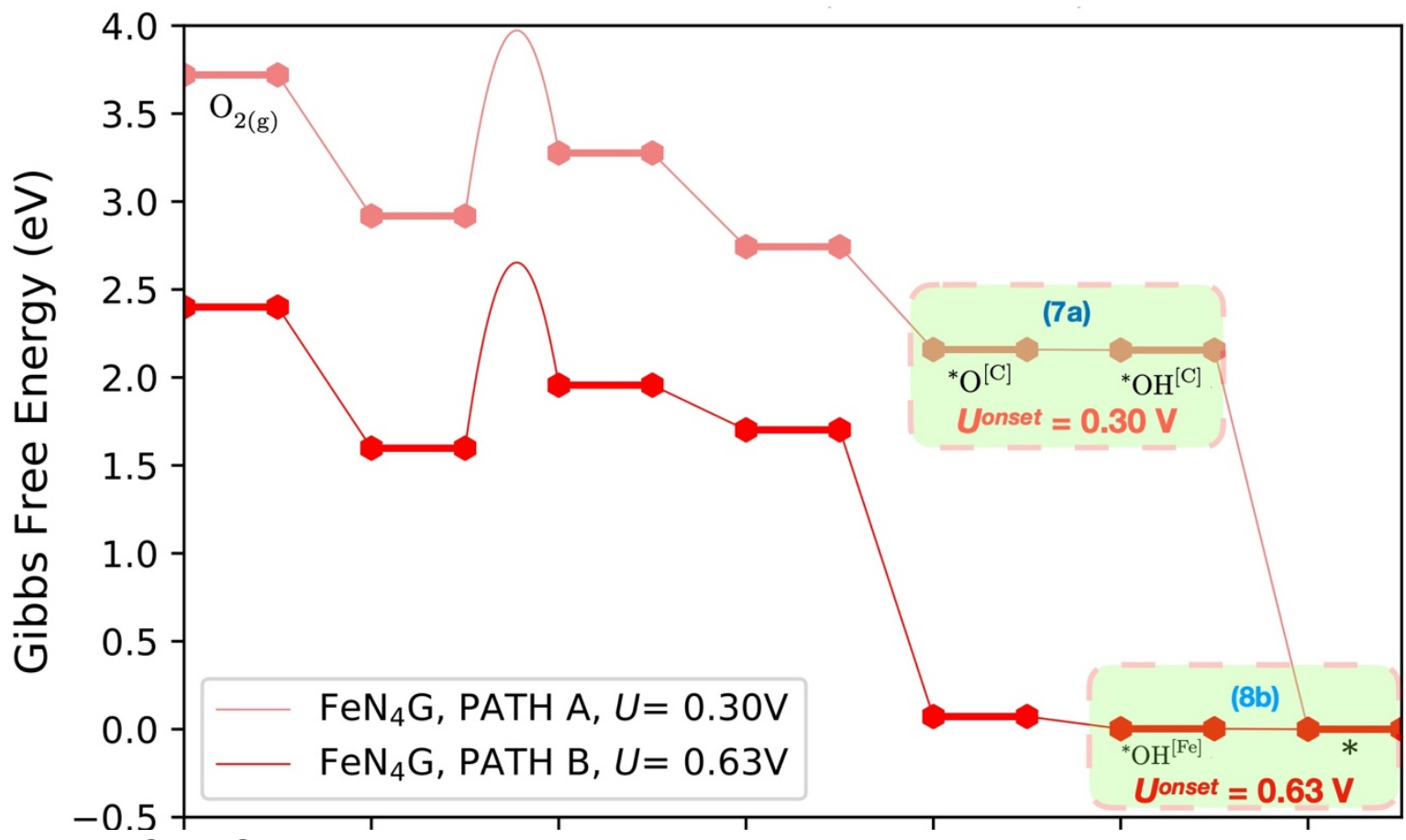

Figure S11. ORR free energy profiles for dissociative mechanism on the undoped $\mathrm{FeN}_{4} \mathrm{G}-\mathrm{BN}$ system at $U=0.30 \mathrm{~V}$ for pathway $\mathrm{A}$ and $U=0.63 \mathrm{~V}$ for pathway $\mathrm{B}$. At these potentials, $\Delta G(U)$ of reaction (7a) and (8b) are equal to zero. The free energy profiles for these reaction pathways start to have uphill profiles at potential higher than these values.

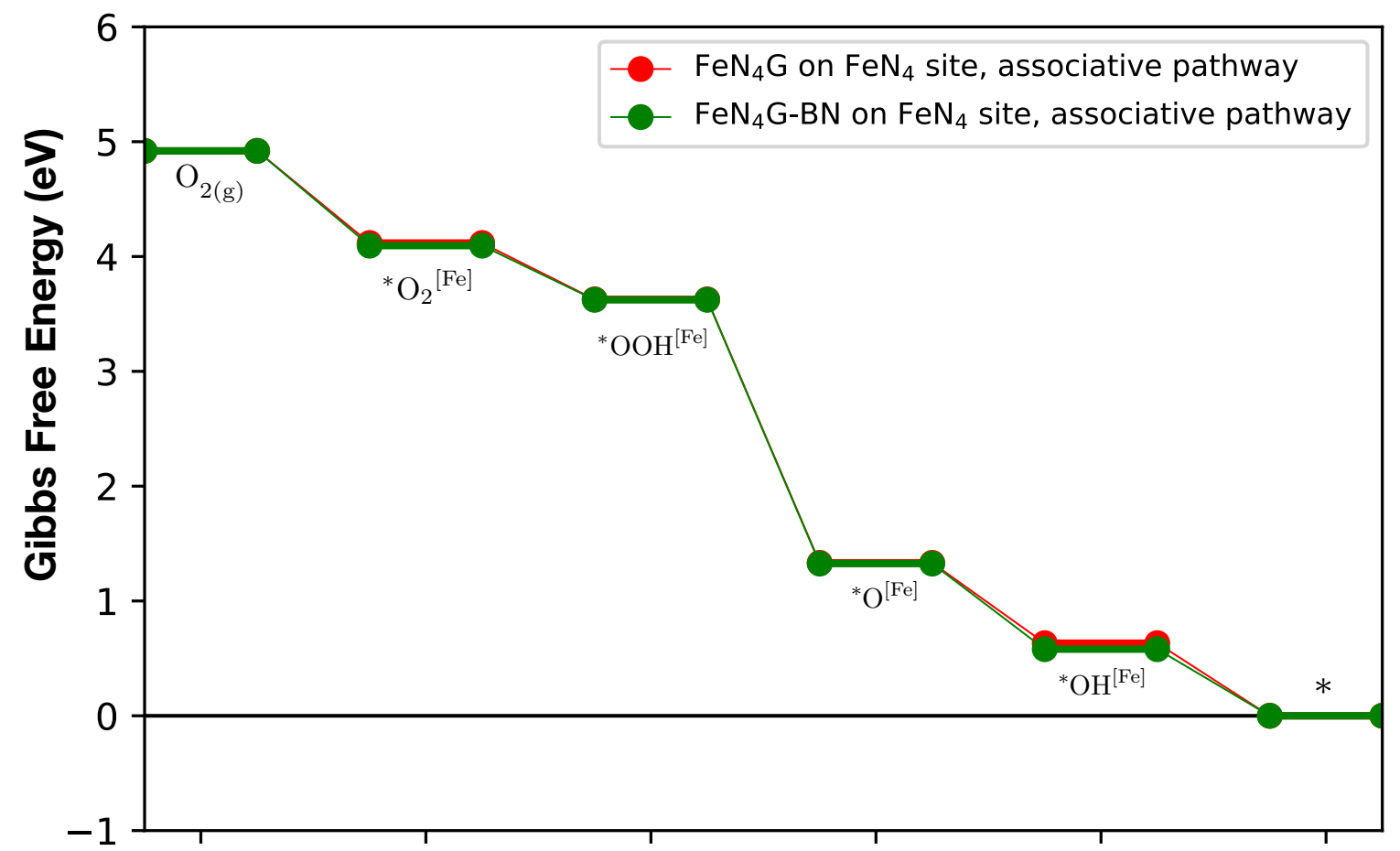

Figure S12. ORR free energy profiles for associative mechanism on the $\mathrm{FeN}_{4}$ site of $\mathrm{FeN}_{4} \mathrm{G}-\mathrm{BN}$ and $\mathrm{FeN}_{4} \mathrm{G}$ systems at $\mathrm{U}=0 \mathrm{~V}$. 


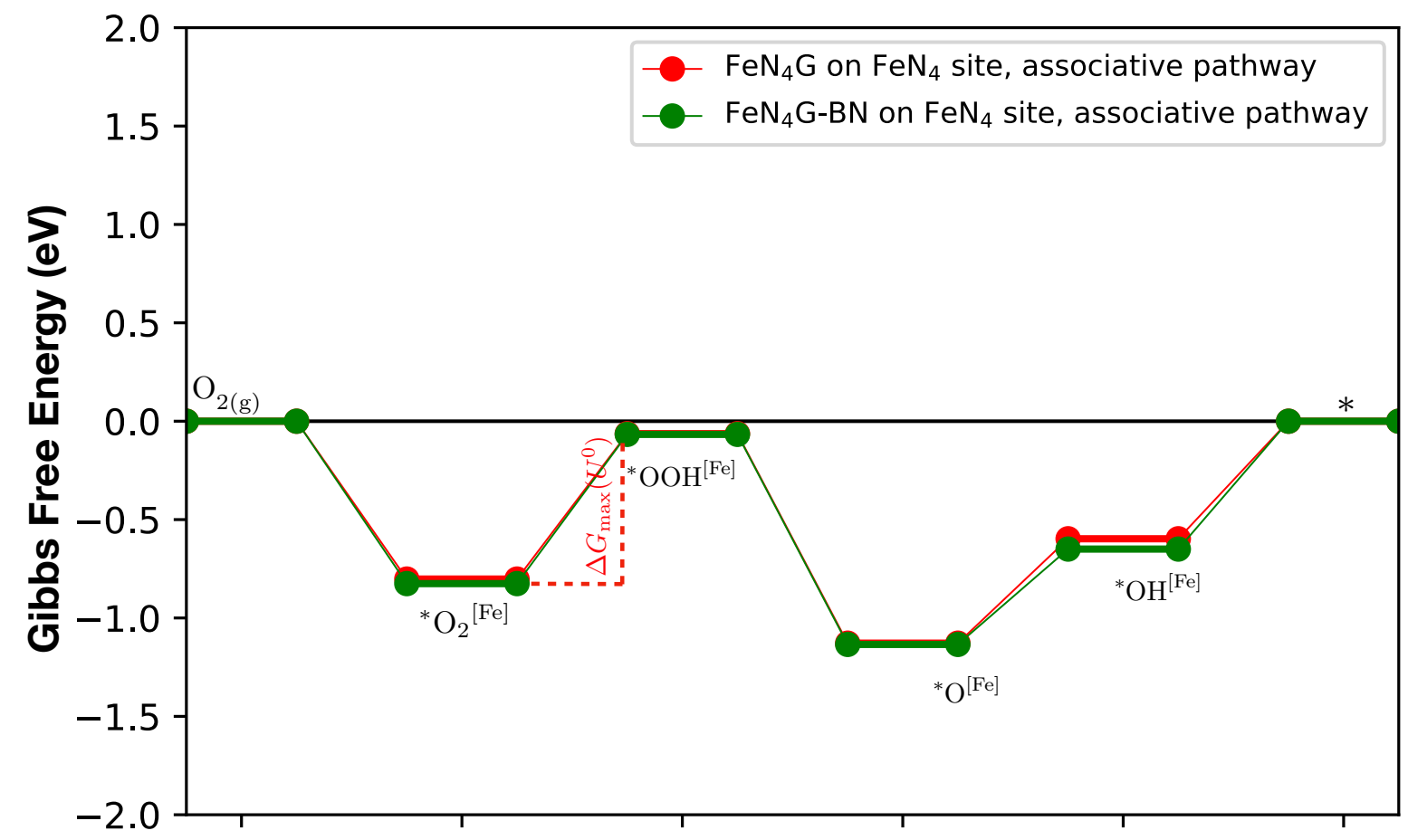

Figure S13. ORR free energy profiles for associative mechanism on the $\mathrm{FeN}_{4}$ site of $\mathrm{FeN}_{4} \mathrm{G}-\mathrm{BN}$ and $\mathrm{FeN}_{4} \mathrm{G}$ systems at $\mathrm{U}=1.23 \mathrm{~V}_{\mathrm{SHE}}\left(\mathrm{U}=0.4 \mathrm{~V}_{\mathrm{RHE}} ; \mathrm{pH}=14\right)$. The elementary steps that give the overpotentials $\left[e \eta=\Delta G_{\max }\left(U^{0}\right)\right]$ on each reaction pathways are indicated in the figure. 


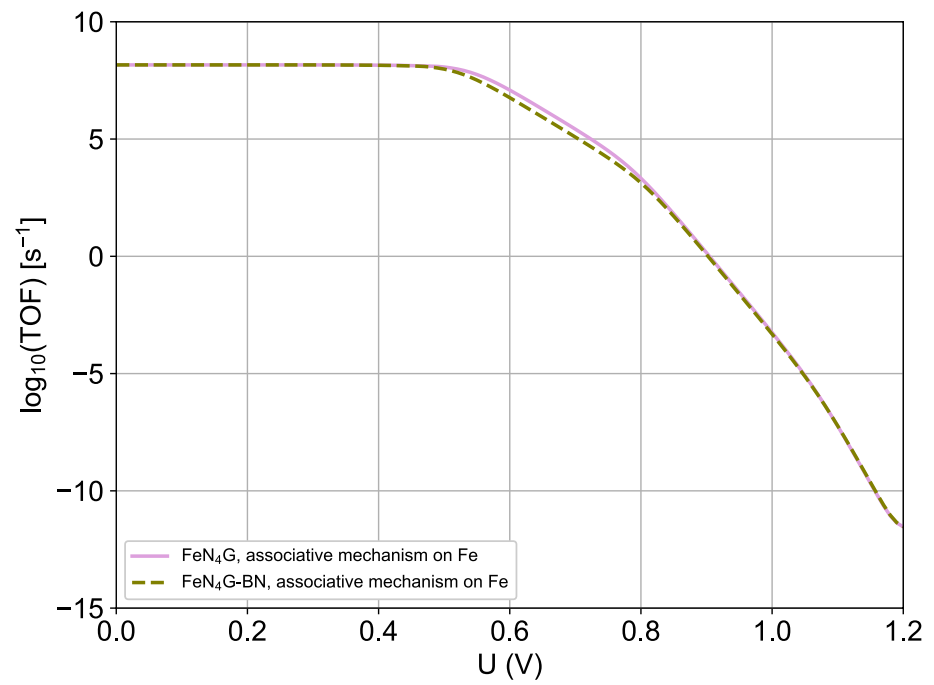

(a)

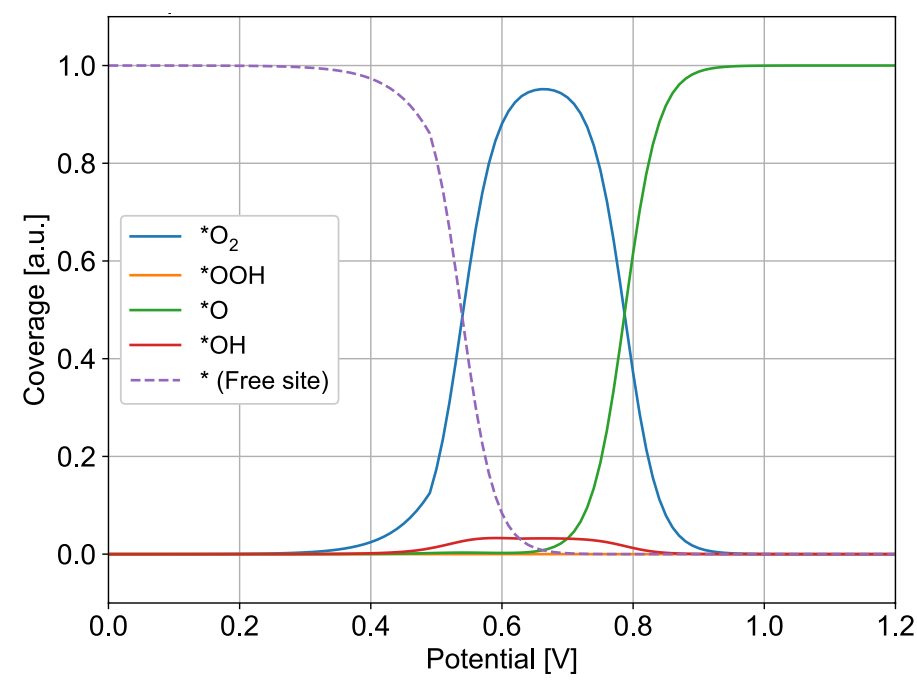

(b)

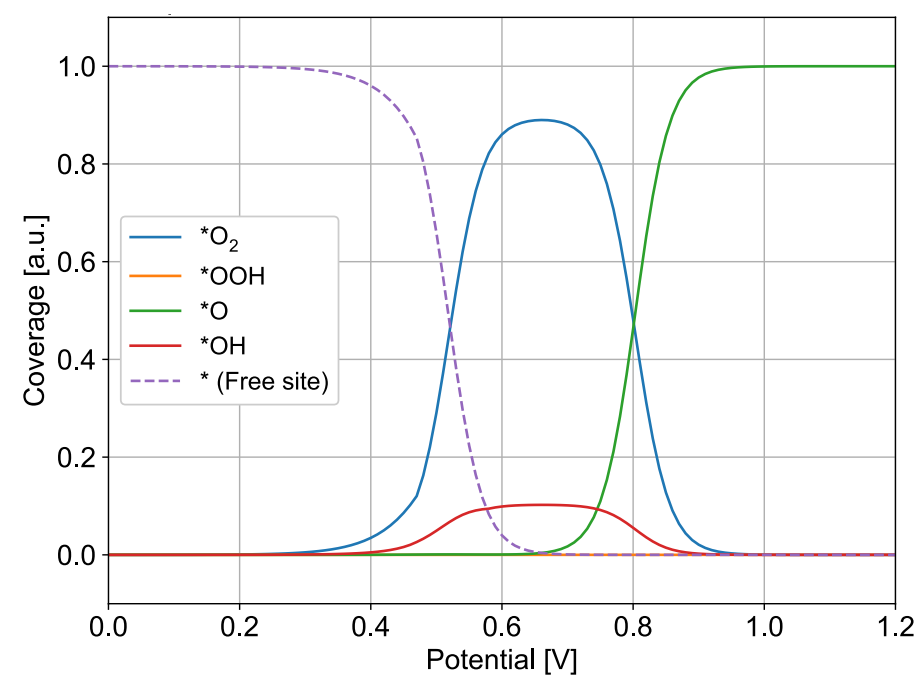

(c)

Figure S14. The (a) TOF profiles and surface coverage profiles for ORR through associative pathway on (b) $\mathrm{FeN}_{4} \mathrm{G}$ and (c) $\mathrm{FeN}_{4} \mathrm{G}-\mathrm{BN}$ systems. 


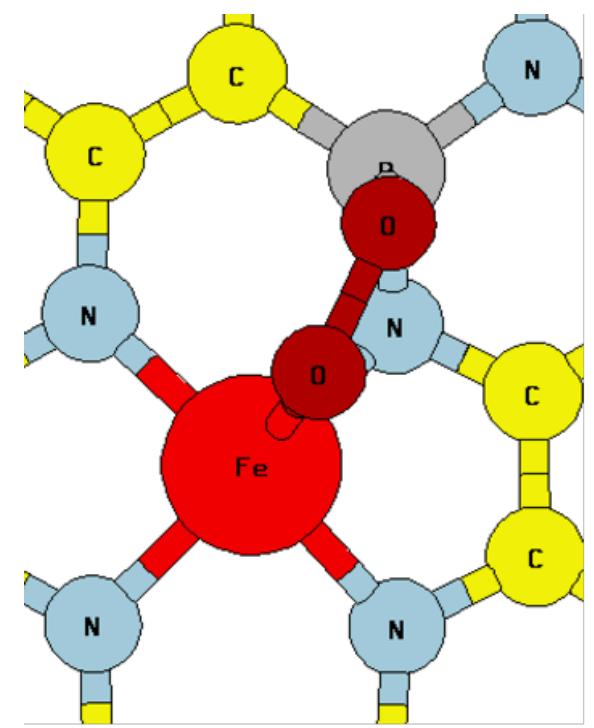

(a)

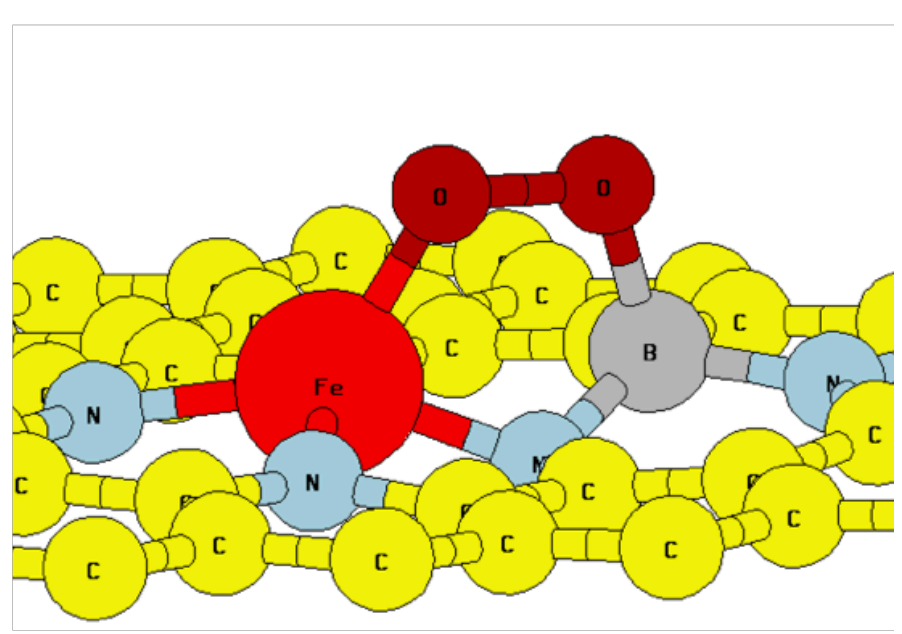

(b)

Figure S15. Top view (a) and side view (b) of the $\mathrm{O}_{2}$ side-on adsorption configuration on the neighboring $\mathrm{FeN}_{4}$ and $\mathrm{B}_{\text {subs }}$ sites.

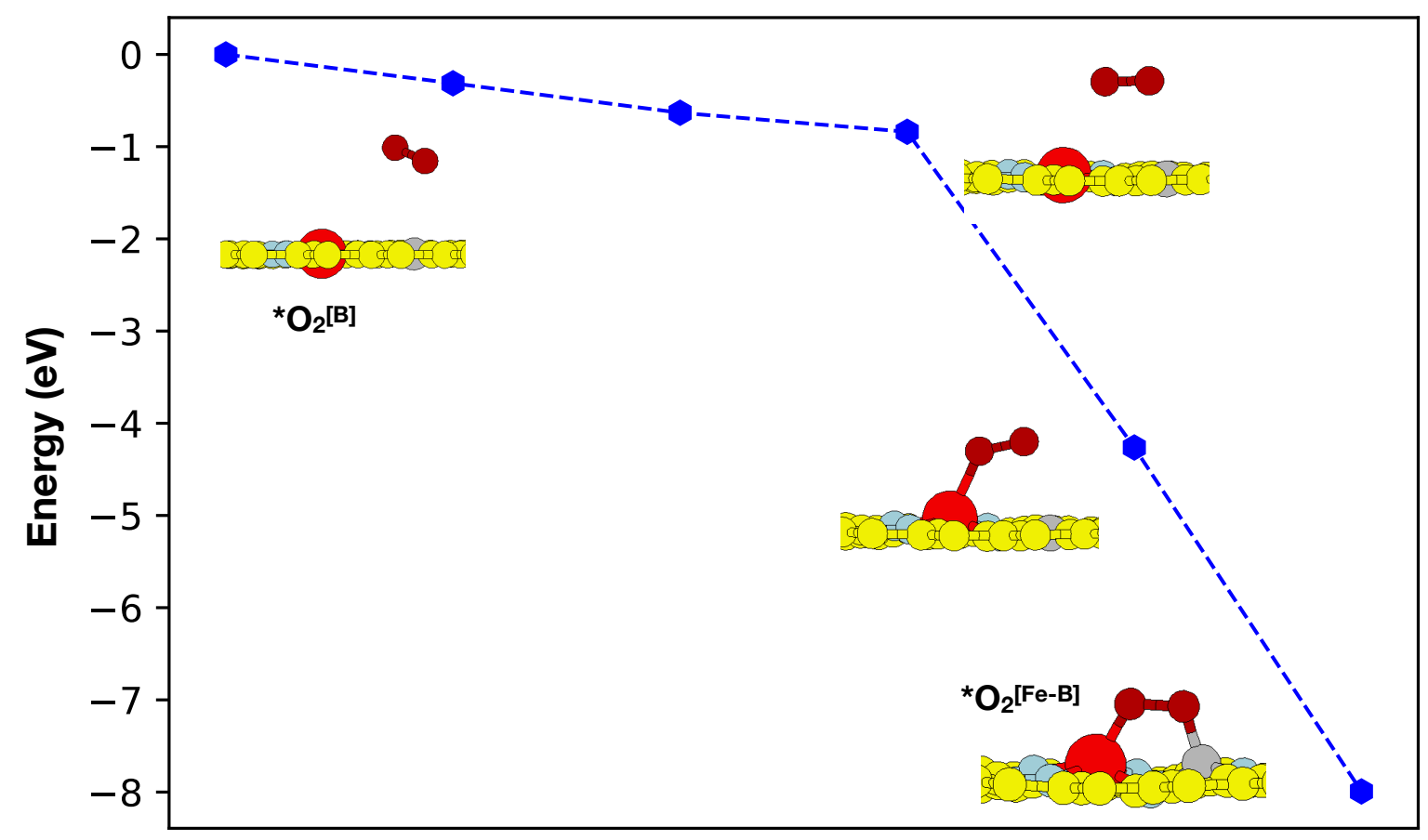

Figure S16. The barrier-less transition of $\mathrm{O}_{2}$ adsorption configuration on the $\mathrm{FeN}_{4} \mathrm{G}$ $\mathrm{BN}$ system from end-on configuration on the $\mathrm{B}$ site to the side-on configuration on the Fe-B sites. 